\title{
TWITTER NO ES UN FORO PÚBLICO PERO EL PERFIL DE TRUMP SÍ LO ES. SOBRE LA CENSURA PRIVADA $D E$ Y EN LAS PLATAFORMAS DIGITALES EN LOS EE UU ${ }^{1}$
}

\author{
Twitter is not a public forum, but Trump's profile is. on \\ private censorship of and on digital platforms in the USA
}

\author{
Víctor J. Vázquez Alonso \\ Profesor de Derecho Constitucional \\ Universidad de Sevilla
}

http://dx.doi.org/10.18543/ed-68(1)-2020pp475-508

Recibido: 10.05 .2020

Aceptado: 12.06 .2020

\section{Resumen}

El objeto de este trabajo es estudiar el reciente desarrollo jurisprudencial en los EE UU, sobre los límites que la Primera Enmienda impone a autoridades y profesionales en el uso de determinadas herramientas de bloqueo en las redes sociales. Para ello, se partirá de sendas resoluciones judiciales que han concluido que el Presidente Trump no puede bloquear en Twitter. Tras ello, y a la luz de la conocida Sección 230 de la Communications Decency Act (CDA), y de la propia jurisprudencia de la Corte Suprema, se va a defender que esta línea jurisprudencial no tiene por qué afectar a la consolidada doctrina que ampara la censura privada que llevan a cabo las empresas tecnológicas de Internet sobre la base de sus libertades corporativas.

\section{Palabras clave}

Libertad de expresión, Internet, Censura privada, Twitter, Trump, Sección 230.

${ }^{1}$ Agradezco a la profesora Ana Galdámez la lectura de este trabajo y sus comentarios y sugerencias. 


\section{Abstract}

The purpose of this work is to study the recent jurisprudential development in the USA, on the limits that the First Amendment imposes on authorities and professionals in the use of certain blocking tools in social networks. For this, it will be based on the two sentences that have concluded that President Trump cannot block on Twitter. After this, and in light of the Section 230 of the Communications Decency Act (CDA), and the jurisprudence of the Supreme Court, it will be argued that this jurisprudential line does not have to alter the consolidated doctrine that protects the private censorship carried out by Internet technology companies on the basis of your corporate liberties.

\section{Key Words}

First Amendment, Internet, Private Censorship, Twitter, Trump, Section 230. 


\begin{abstract}
Sumario: I. Introducción. II. ¿PUede El Gobierno Prohibirte «PASEAR》 POR FACEBOOK? PACKINGHAM V. CAROLINA DEL NORTE. III. ¿Puede@Realdonaldtrump Bloquearte en Twitter?. 1. ¿Qué es un public forum?. 2. ¿De qué hablamos cuando hablamos de Goverment Speech?. 3. ¿Por qué @realDonaldTrump es un foro público?. 4. ¿Por qué no es government speech?. 5. Silenciar vs. Bloquear: entre la legítima ignorancia al ciudadano y su inconstitucional exclusión del foro. IV. LAS REDES SOCIALES NO SON FOROS PÚBLICOS. V. EPÍLOGO DE URGENCIA: TRUMP V. TWITTER Y LA TENTACIÓN DEL CONTRAPODER. BIBLIOGRAFÍA.
\end{abstract}

\title{
I. INTRODUCCIÓN
}

Consolidada ya casi como una cláusula de estilo, la gran mayoría de los trabajos sobre las libertades de expresión e información en la red, comienzan con una apelación, muy poco original, desde luego, a la revolución que ha puesto en curso la irrupción de un nuevo contexto tecnológico, que es el de Internet, en nuestra forma de comunicarnos. Acto seguido, tras dar cuenta de esta obviedad, lo prescrito es tomar de alguna forma partido en un debate que, en muchas ocasiones, se libra entre dos disyuntivas: la de entender que el esqueleto conceptual de las libertades de expresión e información, consolidado en la era pre-digital, no tiene por qué verse alterado ante la nueva realidad tecnológica; o bien, asumir que la revolución digital trae consigo también una suerte de disrupción jurídica en el sistema de la libertad de expresión, debiéndose, por lo tanto, repensar de los presupuestos desde los cuáles hemos venido juzgando los límites al ejercicio de estos derechos.

Esta discusión está también abierta, desde luego, en la propia jurisprudencia. Podemos encontrar, en este sentido, numerosas decisiones en derecho comparado que reconocen esta suerte de zozobra conceptual que rige dentro de un ámbito del ordenamiento que ha visto cómo la realidad cuestiona todo lo que hasta ese momento era sólido. En algunas ocasiones, la reacción a dicha zozobra ha sido una mera relectura en clave restrictiva de los límites a estas libertades, propiciada por una suerte de temor a la que es una de las características definitorias de nuestro «nuevo» marco tecnológico de la libertad de expresión: el potencial viral de cualquier manifestación (Boix Palop, 2016). Sin embargo, más allá de esta jurisprudencia, digamos de repliegue, encontramos también decisiones que de alguna forma dejan ver los elementos verdaderamente, o por lo menos potencialmente, disruptivos del marco conceptual que hasta ahora hemos manejado. Desde luego, se trata de rupturas o alteraciones conceptuales que no afectan a todos los presupuestos epistemológicos de las libertades de expresión e información (de Miguel, 2016). 
Y es que buena parte de ellos, podríamos de decir casi en broma, se asemejan a la rueda; no sólo porque sean un invento perfecto, no susceptible de enmienda, sino también porque sólo sobre ellos hemos podido hacer mover la compleja maquinaria de legitimidad que exige la forma democrática de gobierno (Habermas, 2009: 261-274 y 2002: 220).

En cualquier caso, si en algo parece haberse dado una alteración sustancial es en aquello que podríamos denominar como la ecología de la libertad de expresión. Es decir, el medio, el foro en el que principalmente ahora vamos a relacionarnos en el ejercicio de estas libertades, y desde el cual, se va a construir la opinión pública. Pero, al hablar de foro, podemos estar induciendo al error por simplificación, y es que, al referirnos a la red, debemos hablar de foros y subforos, donde lo realmente problemático va a ser poder dirimir la naturaleza de los mismos y con ello, el propio principio de autoridad para regular el discurso dentro de ellos. Nos encontramos, por lo tanto, en un contexto en el que la separación clásica entre foros públicos y foros privados parece difuminarse, cobrando cada vez más importancia, como parte integrante de la libertad de expresión protegida, la idea del «derecho de acceso al foro» como presupuesto para la plena participación de nuestras ideas o juicios de valor en el debate público (Teruel, 2017: 81 y ss).

A este respecto, todos estamos de acuerdo en que las redes sociales no son medios de comunicación al uso. Los medios de comunicación han desarrollado su actividad desde el inicio, disfrutando de una discrecionalidad excepcional para llevar a cabo un control de sus contenidos. Esta censura interna se justificaba, en primer lugar, como un instrumento de fiscalización interna que garantizaba la posibilidad de hacer reconocible la orientación editorial del medio en el mercado de la comunicación. En definitiva, la propia libertad ideológica del medio ${ }^{2}$. Por otro lado, el control de los contenidos en el mundo periodístico ha sido y es un instrumento fundamental para que los medios de comunicación puedan evitar incurrir en responsabilidades jurídicas por la publicación de aquellos contenidos que ellos editen, dentro de un sistema de responsabilidad civil subsidiaria (Balkin, 2012).

Como es conocido, la lógica de este sistema quiebra en la nueva sociedad de la información, donde la mayor parte de los agentes intermediarios van a prestar sus servicios partiendo desde lo que podríamos calificar como: una aspiración originaria a la neutralidad y el pluralismo ${ }^{3}$. Aspiración luego

${ }^{2}$ Vale hacer referencia que a la cita que, en clave originalista, hace la Corte Suprema a Benjamin Franklin quien afirmaba no dirigir su periódico como «a stagecoach, with seats for everyone.» Manhattan Community Access Corp . v. Halleck, 587 US _ 6 (2019). La cita original, la toma la Cote de Mott, F, American Journalism 55 (3d ed. 1962).

3 Para un análisis que desmitifica desde la praxis estos ideales, sigue estando vigente el texto de (Boix, 2002). 
reforzada normativamente a través de un régimen, por lo menos hasta ahora -y aunque como veremos haya diferencias a uno y otro lado del Atlántico ${ }^{4}-$ muy beneficioso de exención de responsabilidad por los contenidos introducidos por terceros. Este ideal regulador de neutralidad y apertura, unido al hecho de que determinadas empresas como Google, Facebook o Twitter han casi monopolizado, como plataformas tecnológicas, ciertos servicios en el nuevo sistema de comunicación, hace que, para muchos, sea más realista ver a esas empresas como una suerte de instituciones de la sociedad de la información, y a los foros que en ellas se generan como foros asimilables a aquello que hasta ahora hemos comprendido como foros públicos.

Sin embargo, como decíamos, Internet ha producido cambios en nuestra comprensión jurídica del sistema de la libertad de expresión, pero no un seísmo conceptual. A este respecto, y de la mano de la jurisprudencia norteamericana, y especialmente a partir del ya célebre litigio originado por los bloqueos en Twitter del Presidente Trump, intentaré demostrar aquí cómo, si bien el concepto constitucional de foro público se extiende a ciertos ámbitos digitales, la jurisprudencia norteamericana está lejos de asumir que dicho concepto sea extensible a los foros creados y gestionados por las grandes empresas tecnológicas de la comunicación como Twitter, Facebook o YouTube, algo que tiene una importancia trascendental a la hora de dar respuesta a una de las principales cuestiones que hoy se plantean en relación al control que estas plataformas puedan llevar a cabo sobre el discurso, y que es el de la naturaleza privada o pública de esta censura. Frente a quienes demandan, dada la posición institucional monopolística de estas corporaciones, una asimilación de sus tareas de control a la de los poderes públicos, en los Estados Unidos, y al contrario de lo que podía apuntarse hace apenas dos años, la teoría de la State Action sigue disfrutando de buena salud, de tal forma que estas compañías pueden operar al margen de los requisitos exigidos por la Primera Enmienda. Estas compañías sí, pero las instituciones o autoridades públicas que las utilizan no, veamos por qué.

\section{II. ¿PUEDE EL GOBIERNO PROHIBIRTE «PASEAR»POR FACEBOOK? PACKINGHAM V. CAROLINA DEL NORTE}

En el año 2017 la Corte Suprema norteamericana dictó una decisión sobre la que se pudo pensar, y así lo entendieron algunos autores, que era posible construir una nueva teoría del foro público extensible a las redes sociales. Se trata de la sentencia Packingham v. Carolina del Norte, y su origen se

${ }^{4}$ Para una panorámica comparativa resulta especialmente ilustrativo el trabajo de (Presno, Teruel, 2017).

${ }^{5}$ Packingham v. Carolina del Norte, 582 US (2017). 
encuentra en una ley de este Estado, Carolina del Norte, que tipifica como delito el acceso a «sitios web comerciales» ${ }^{6}$ por parte de delincuentes sexuales convictos, cuando estos supieran que dichos sitios permiten que los menores puedan darse de alta como miembros o crear páginas web con su perfil personal. Quien recurre ante la Corte Suprema es un ciudadano que había cumplido condena por mantener relaciones sexuales con un menor de trece años cuando él era un estudiante de 21 . Tal y como prescribía la legislación estatal, al salir de prisión fue dado de alta en un registro de delincuentes sexuales que sirvió de base para que la policía contrastara su presunto comportamiento ilícito ${ }^{7}$, consistente en, tras haber conseguido anular una multa de tráfico, expresar a través del Facebook su alegría con estas inofensivas palabras:

«Man God is Good! How about I got so much favor they dismiss the ticket before court even started. No fine, No court costs, no nothing spent... Praise be to GOD, WOW! Thanks JESUS!»

El jurado que conoció del caso entendió que la red social Facebook sería subsumible, por sus características, dentro del concepto «sitio web comercial», cuyo acceso estaba especialmente vedado a los delincuentes sexuales ${ }^{8}$, y encontró culpable al acusado. Desde ese momento, el argumento central sobre el que el recurrente estructura su defensa en las sucesivas instancias es que dicha ley, que prohíbe el mero acceso a determinadas plataformas digitales por parte de condenados por delitos sexuales, es una ley que vulnera el derecho a la libertad de expresión consagrado en la Primera Enmienda. Una vulneración que los jueces de la Corte Suprema van a constatar de forma unánime.

${ }^{6}$ Para el legislador estatal, por «sitio web comercial» habría de entender aquel en el que se cumplen cuatro requisitos concretos:

${ }^{\mathrm{E}} \mathrm{n}$ primer lugar, dicha página tiene que estar gestionada por una persona o entidad que obtiene réditos a través de las cuotas que pagan sus miembros o de los ingresos por publicidad o también, especifica la ley, a través de otras fuentes vinculadas al funcionamiento del sitio web. En segundo lugar, dicha página debe potencialmente facilitar el encuentro entre dos o más personas «con el propósito de amistad, conocer a otras personas o intercambiar información». En tercer lugar, la página ha de facilitar a los usuarios crear páginas web o perfiles personales que contengan datos como el nombre o apodo del usuario, fotografías u otra información personal sobre el usuario. Finalmente, la página ha de poner a disposición de los usuarios o a sus visitantes mecanismos para comunicarse con otros usuarios a través de chat, correo electrónico o mensajería instantánea.

${ }^{7}$ De hecho, aunque no sea este el objeto de nuestro trabajo, la sentencia Packingham v. Carolina del Norte tiene también importantes implicaciones en lo referido al tratamiento policial de archivos.

${ }^{8}$ Hay que subrayar que en ningún momento pudo demostrarse que el recurrente había entrado en contacto con menores a través de dicha red. A lo único que éste se había limitado es a expresar públicamente una opinión utilizando la misma. 
Esta unanimidad creo que puede calificarse de predecible. La Corte Suprema no se enfrentaba aquí a lo que conocemos como un caso difícil. Más bien al contrario. Tomando en consideración la generosa comprensión de la libertad de expresión y sus límites que ha caracterizado a esta jurisdicción, específicamente a los años de la Corte Roberts, era fácil prever el sentido del fallo. Expresar públicamente Man God is Good! está muy lejos de entrar en el terreno propio de ese discurso que puede generar un «peligro real y cierto», criterio a partir del cual legítimamente podría ser objeto de censura estatal ${ }^{9}$. Nos encontramos aquí ante una política legislativa que toma en consideración el perfil de la víctima en los delitos sexuales a través de la red -que es el de menores que se ven expuestos a la acción de depredadores digitales- pero que cifra la conducta típica, el acceso a ciertos servicios en red, de una forma tan vaga e indeterminada que permite su aplicación, como en este caso, a manifestaciones del todo veniales y que caen, de manera no controvertida, bajo el amparo de la libertad de expresión.

Ahora bien, pese a tratarse de un caso fácil, el enfoque a través del cual la Corte aborda el mismo lo convierte en un precedente especialmente importante para futuras decisiones sobre el alcance de la protección de la Primera Enmienda en el ámbito digital. Dicho enfoque, arquetípico, por otro lado, dentro de la jurisprudencia norteamericana, es el del forum analysis. Se trata, dicho de otra forma, de una aproximación a la libertad de expresión de la Primera Enmienda entendida como derecho al foro ${ }^{10}$, solo que ahora trasladada al ámbito puramente digital ${ }^{11}$. La cuestión, por lo tanto, no versa ya sobre los posibles límites al discurso, sino sobre el derecho a estar presente y a ser potencialmente activo en un medio o contexto comunicativo como es en este caso Facebook, que no deja de ser una plataforma privada.

${ }^{9}$ En nuestra doctrina y sobre los USA, puede verse una excelente panorámica en (Alcácer, 2015).

${ }^{10}$ Lo cual, por otro lado, tiene mucho que ver con el hecho de que sea un juez como Kennedy, conocido defensor de la portabilidad de la doctrina del foro público a ámbitos no tangibles. Es conocido, en este sentido, su voto particular a la sentencia Denver Area Educational Telecommunications Consortium vs. Federal Communications Commission, 518 U.S. 727, (1996), donde, al contrario que la mayoría del Tribunal, Kennedy entiende que el espacio televisivo es una suerte de «versión electrónica» de los parques públicos, de tal forma que «in return for granting cable operators easements to use public rights-ofway for their cable lines, local governments have bargained for a right to use cable lines for public access channels . no particular formalities are necessary to create an easement . when a local government contracts to use private property for public expressive activity, it creates a public forum» (793-794) (Las cursivas son mías).

${ }^{11}$ En nuestra doctrina, puede verse un estudio pionero sobre la adaptación de la doctrina de la Corte Suprema sobre la libertad de expresión a la realidad de Internet en (Rodríguez Izquierdo, 2013). 
Lo cierto es que, desde esta perspectiva, la problemática que se plantea en Packingham v. Carolina del Norte era inédita en muchos aspectos. De hecho, los dos litigios que fueron citados durante las audiencias como posibles precedentes aplicables al caso, en realidad respondían a controversias cuya analogía con la planteaba Packingham es, en mi opinión, bastante difusa.

En el primero de ellos, Burson v. Freeman ${ }^{12}$, la Corte Suprema consideró que no era contraria a la Primera Enmienda la prohibición que establecía el Estado de Tennessee de realizar actos de campaña electoral a menos de 100 pies de un lugar de voto, al considerar la mayoría del Tribunal que se trataba de una medida que respondía razonablemente al objetivo de garantizar el derecho al sufragio. El otro precedente invocado, y en último término el que es tomado en consideración por la Corte para justificar su fallo, es Board of Airport Commissioners of Los Angeles v. Jews for Jesus, Inc. ${ }^{13}$, en el que se consideró contraria a la Primera Enmienda la prohibición general que establecía una ordenanza del Aeropuerto Internacional de los Ángeles, de llevar a cabo cualquier tipo de actividad relacionada con la Primera Enmienda en sus dependencias. Se trataba, como apuntaba en su opinión la juez O'Connor, de una suerte de exclusión general de la libertad de expresión en un espacio público, que no podía encontrar justificación constitucional.

Ahora bien, como decíamos, lo que se juzga en Packingham es algo muy diferente. Y lo es, primero, porque la restricción a la libertad de expresión ya no se proyecta, en este caso, sobre un espacio físico. Y, en segundo lugar -y también lo más relevante aquí- porque dicha prohibición afecta al mero acceso a plataformas digitales que son creadas y gestionadas por corporaciones privadas.

La relevancia de la doctrina del foro público en el ámbito digital ya fue advertida por la propia Corte Suprema en Reno v. American Civil Liberties Union $^{14}$. Un precedente que puede considerarse no solo pionero sino en cierto modo visionario de en qué medida la nueva realidad tecnológica iba a afectar a presupuestos básicos del sistema de libertad de expresión y de los propios procesos de formación de la opinión pública. A este respecto, como es conocido, el juez Stevens, quien relataba la opinión de la Corte, no dudó en identificar la red como «un vasto foro democrático» ${ }^{15}$, sugiriendo, de alguna forma, que la naturaleza de esta esfera era análoga a las de los clásicos foros públicos. Ahora bien, si esta calificación genérica del ciberespacio como un vasto foro democrático fue certera desde un punto de vista

${ }^{12}$ Burson v. Freeman, 504 U. S. 191 (1992).

${ }^{13}$ Board of Airport Commissioners of Los Angeles v. Jews for Jesus, Inc., 482 U.S. 569 (1987).

${ }^{14}$ Reno v. American Civil Liberties Union, 521 U. S. 844, (1997).

15 Reno v. American Civil Liberties Union, 521 U. S. 844, 868 (1997). 
prospectivo y sociológico, desde un punto de vista estrictamente jurídico, la misma no ha dejado de platear problemas de funcionalidad. Problemas que tienen que ver con la propia heterogeneidad del ciberespacio, cuya naturaleza hoy en día no es tanto la de un foro como la de un foro de foros de muy diversa naturaleza.

Más de veinte años después de Reno, en Packingham v. North Carolina la Corte es ya consciente de este tránsito, y no es casual que, en este caso, donde se trata de juzgar la prohibición de acceso a una concreta red social, los jueces insistan en que se encuentran ante su primer litigio relacionado con el «internet moderno». Un Internet que, dentro de su versatilidad, tendría como elemento común el hecho de que es a través del mismo donde la voz del ciudadano puede hoy encontrar su plenitud en muy diversas esferas ${ }^{16}$.

Constatada esta incerteza, el Tribunal va a establecer una suerte de principio general a favor de la libertad de acceso a la red, instando a la «extrema precaución frente a la sugerencia de que la Primera Enmienda proporciona una protección escasa para el acceso a estas redes» ${ }^{17}$. Redes que son hoy, insiste la Corte, los espacios de mayor relevancia en la discusión democrática, desplazando inequívocamente a otros lugares hasta hora trascendentales, como plazas y calles, para el intercambio de ideas.

El legítimo interés del Estado para prevenir el delito en estos foros, $\mathrm{y}$, en su caso, para censurar discursos de naturaleza ilícita que, valiéndose de la propia tecnología de la red, puedan resultar especialmente lesivos, podrá ser considerado como fundamento válido para ciertas restricciones, pero no para una suerte de destierro digital como el que la ley de Carolina del Norte prevé para los condenados por delitos sexuales. En definitiva, no se puede impedir el acceso a aquellas plataformas digitales sin las cuales el individuo no puede hoy tener un desarrollo pleno de su vida en sociedad: plataformas que le permiten «ser pregonero de su propia voz».

En cualquier caso, como decíamos en un principio, Packingham v. North Carolina es un caso fácil, y por ello, sus propias premisas, aunque aquí

${ }_{16}$ No deja de ser llamativa esa continua sensación de deslumbramiento que este medio sigue produciendo sobre los operadores jurídicos, ya muchos años después de su irrupción, la comunicación en red. Valga como ejemplo la manera en que la propia Corte sigue aquí subrayando su inseguridad en este ámbito:

«La naturaleza de una revolución puede ser tal que, en sus primeras etapas, incluso sus participantes no sean conscientes de ello. Y que, cuando lleguen a serlo, aún sean incapaces de saber o prever a dónde nos llevan esos cambios Si bien ahora podemos darnos cuenta de que la Era Cibernética es una revolución de magnitudes históricas, aún no podemos apreciar sus dimensiones completas y su vasto potencial para alterar nuestra forma de pensar, expresarnos y definir quién queremos ser» Packingham v . Carolina del Norte, 582 US _, 6 (2017).

17 Packingham v. Carolina del Norte, 582 US __, 6 (2017). 
concluyentes, abren muchos interrogantes si las intentamos proyectar sobre otras realidades potencialmente conflictivas que se producen de forma cotidiana en las redes sociales. Es especialmente relevante a este respecto, como veremos, que el Tribunal se cuide mucho de afirmar de forma explícita que dichas redes son «foros públicos», siendo consciente, a buen seguro, del problema conceptual que plantea usar dicho adjetivo para definir la naturaleza de lo que no dejan de ser corporaciones privadas y de las propias implicaciones jurídicas que tendría sostener dicha afirmación de forma rotunda y general. Nada dice el Tribunal, en este sentido, de cómo han de juzgarse aquellos límites que las plataformas digitales decidan imponer a determinados contenidos. Lo que sí se establece, en cualquier caso, es el principio de que los poderes públicos están estrictamente vinculados al escrutinio de la Primera Enmienda, cuando estos impongan cualquier traba en el acceso foros digitales por parte de los ciudadanos.

No obstante, como ha señalado algún autor, mientras la Corte discutía sobre Packingham v. North Carolina, había un elefante en la habitación (David T. Goldberg y Zhang, 2017) y ese elefante era el timeline de @realDonaldTrump, es decir, del ya en ese momento Presidente de los Estados Unidos. Se sabía, en buena medida, que esta doctrina judicial que somete a un estricto escrutinio cualquier límite que los poderes públicos impongan en el acceso a las redes sería determinante para dar respuesta jurídica a una pregunta: ¿Puede @realDonaldTrump bloquearte en Twitter?

\section{III.¿PUEDE@REALDONALDTRUMP BLOQUEARTE EN TWITTER?}

Siete ciudadanos norteamericanos, descontentos con algunas de las políticas llevadas a cabo por la administración Trump, utilizaron el perfil del presidente en Twitter, @realDonaldTrump,para manifestar su discrepancia a través de comentarios críticos a alguno de sus tuits. Como consecuencia de ello, el presidente Donald Trump decidió bloquear a estos usuarios, un hecho que provocó que una juez norteamericana haya dado respuesta a la cuestión de si es contrario a la libertad de expresión consagrada en la Primera Enmienda, el que una autoridad pública decida bloquear el acceso a determinados usuarios como consecuencia de las opiniones críticas que éstos hayan esgrimido. La respuesta ha sido afirmativa. Se trata de una decisión en primera instancia, en concreto, del Tribunal del distrito sur de Nueva York ${ }^{18}$, si

${ }_{18}$ Knight First Amendment Institute At Columbia University v. Trump., United States District Court

${ }^{\mathrm{s}}$ outhern District Of New York, May 23, 2018. (En Adelante, Knight First Amendment Institute $\mathrm{v}$. Trump) 
bien la misma ha sido ratificada por un Tribunal de Apelaciones el Segundo Circuito que avala casi íntegramente el razonamiento de la juez de Manhattan ${ }^{19}$.

En cualquier caso, por el actor implicado, nada menos que el Presidente de los Estados Unidos, pero sobre todo por las propias características del litigio, en el caso Knight First Amendment Institute v. Trump cristalizan muchos de los interrogantes que hoy se plantean en cualquier democracia pluralista, en relación a cuáles son los límites constitucionales que se imponen al uso que las instituciones públicas puedan hacer, en su acción de gobierno, de determinadas herramientas tecnológicas de comunicación que ofrecen las empresas privadas y que se caracterizan por ser abiertas e interactivas. En el derecho norteamericano la respuesta a estas cuestiones pasa necesariamente por el análisis de dos conceptos que son centrales en la doctrina sobre la libertad de expresión desarrollada por la Corte Suprema norteamericana en las últimas décadas. Estamos hablando del concepto jurídico de public forum y del de goverment speech. El primero de ellos, al que ya hemos hecho mención, hace alusión a aquellos espacios bajo el control del Estado que a su vez constituyen un foro de discusión de libre acceso para los ciudadanos, y donde no cabría ninguna limitación a esta libertad que tenga como razón de ser el contenido ideológico de las opiniones que estos pudieran emitir: lo que en derecho norteamericano se conoce como view point discrimination. El concepto de government speech, por su parte, sirve para circunscribir la responsabilidad del gobierno por su discurso ideológico como una responsabilidad exclusivamente política y no jurídica. Cuando es el gobierno el que habla, en definitiva, no es posible, sobre la base de la Primera Enmienda, exigir que lo haga de forma neutral. Pues bien, a continuación llevaremos a cabo, en primer lugar, una aproximación a ambos conceptos sintetizando el desarrollo que han tenido en la jurisprudencia de la Corte Suprema. Todo ello para después contrastar la forma en la que el Tribunal del Distrito Sur New York ha dado respuesta a la pregunta de si un cargo representativo o una autoridad pública vulnera mi libertad de expresión si decide bloquear mi acceso a su cuenta en una red social.

\section{1. ¿Qué es un public forum?}

Como señalábamos a propósito de Packingham v. Carolina del Norte, el denominado forum analysis, sobrevuela cualquier discusión sobre las posibles restricciones que puedan establecerse al acceso de ciertos discursos en el ámbito digital. Es importante, por lo tanto, concretar cuál es el concepto de

19 Knight First Enmienda Inst. en Columbia Univ. v. Trump, No. 1: 17-cv-5205 (SDNY), No. 18-1691 (2d Cir.). 
foro público que ha desarrollado la jurisprudencia norteamericana, y qué implicaciones tiene el mismo. La doctrina public forum tiene su origen en la Corte Suprema de finales de la década de los treinta, es decir, en el seno de un Tribunal en el que ya se ha producido un tránsito con respecto al catecismo liberal propio de la Era Lochner, pero en el que, al mismo tiempo, se consolidaba la doctrina de la incorporación de The Bill of Rights a los Estados, que, sentará las bases para la verdadera revolución liberal que experimenta el derecho constitucional norteamericano durante los posteriores años de la Corte Warren. Hasta finales de los años treinta, de la mano de un apego todavía notable al Common Law, la Corte Suprema norteamericana había sostenido una tesis radical con respecto a los límites que el Estado puede imponer a la libertad de expresión de los ciudadanos en aquellos espacios que están bajo su dominio. Unos límites que no diferían de aquellos que cualquier otro ciudadano podría establecer en lugares de su propiedad. La ruptura con esta doctrina se producirá a través de un caso, Hague v. Committee for Industrial Organization ${ }^{20}$, relacionado con manifestaciones públicas de carácter sindical, una materia especialmente sensible para un Tribunal que intentaba redimirse de la contrarrevolución que en materia de derechos sociales había protagonizado frente a buena parte de la legislación del New Deal. El nuevo principio que esboza la Corte podría resumirse en que allí donde exista un espacio público, como lo son las calles, en el que sea costumbre que los ciudadanos expresen sus opiniones, los poderes públicos no pueden llevar a cabo ninguna regulación que limite determinados discursos por razón de su contenido ideológico ${ }^{21}$. Esta doctrina, entonces germinal ${ }^{22}$, sobre los límites que impone la Primera Enmienda a los poderes públicos a la hora de restringir el acceso a ciertos foros, va a ser desarrollada en las décadas siguientes, dando lugar a una triple distinción.

Así, la Corte distingue, en primer lugar, los foros públicos tradicionales, tales como calles y parques, que siempre han estado abiertos a que los ciudadanos puedan hacer uso de ellos para expresar sus opiniones, en los que el

${ }^{20}$ Hague vs. Committee for Industrial Organization, 307 U.S. 496 (1939)

${ }^{21}$ Como suele ocurrir en derecho norteamericano, desde la sentencia Hague v. Committee for Industrial Organization hasta que la Corte Suprema apele expresamente al término de foro público, y determine sus contornos jurídicos como canon de constitucionalidad, van a pasar varias décadas durante las cuales la doctrina académica lleva a cabo una importante labor de exégesis e intermediación. En este caso, fue el profesor Harry Kalven quien, a propósito de la muy conocida sentencia Cox v. Louisiana apuntó al hecho de que, de forma implícita, la Suprema Corte había desarrollado un concepto jurídico de foro público para identificar aquellos espacios bajo su dominio en los que el Estado no podría regular libremente el ejercicio de la libertad de expresión.

22 Chicago Police Dept. v. Mosley, 408 U.S. 92 (1972). 
Estado no puede imponer más límites a la libertad de expresión que aquellos que pudieran estar justificados en un interés apremiante ${ }^{23}$.

Pero, junto a estos foros, digamos naturales, la jurisprudencia de la Corte Suprema ha distinguido un segundo tipo de public forum, que serían aquellos que han sido habilitados específicamente por el Estado para tal fin, lo que en derecho norteamericano se conoce como designated public forum. Se trata, en definitiva, de espacios de titularidad pública que en su origen no servían como lugar para la libre expresión de los ciudadanos, pero que posteriormente han sido destinados a tal efecto por parte de los poderes públicos. Lo relevante en cualquier caso es que, para la Corte Suprema, la libertad de expresión de la Primera Enmienda tendrá en estos foros artificiales el mismo nivel de protección que en aquellos considerados naturales, de tal forma que el Estado sólo podrá restringir el discurso de los ciudadanos cuando esgrima un interés público apremiante que lo justifique.

Como una subcategoría dentro de los degisnated public forum, aunque no del todo bien perfilada en la jurisprudencia de la Corte Suprema, encontramos la noción de limited public forum, que hace referencia, en este caso, a aquellos ámbitos del dominio público que el Estado ha querido abrir al ejercicio de la libertad de expresión por parte de los ciudadanos, pero circunscribiendo a priori cuál ha de ser el contenido o el objeto de la discusión que allí puede expresarse, y el perfil de quienes están convocados a participar. En este ámbito, por lo tanto, el poder público podrá excluir ciertos discursos sin con ello vulnerar la Primera Enmienda, siempre y cuando la razón de esa exclusión sea que los mismos se apartan del objeto para el cual dicho foro fue creado. Ahora bien, dentro del ámbito material para el que se creó el foro, no cabe ningún tipo de restricción que tenga causa en la orientación ideológica del mismo. En definitiva, en los limited public forum rige la regla de que no cabe ningún tipo de view point discrimination, si bien, como cualquiera puede intuir, no siempre es fácil deslindar aquellos límites impuestos a determinados discursos sobre la base de su inadecuación temática, de los que tienen causa en la falta de neutralidad ideológica de la institución.

En último lugar, la Corte Suprema ha distinguido una tercera categoría, el non public forum, integrada por aquellas propiedades de dominio estatal que ni por tradición ni tampoco de forma premeditada han sido destinadas como foros para la discusión ciudadana. Aquí los límites que el Estado quiera imponer sobre la libertad de expresión a aquellos ciudadanos que deseen acceder a estos foros, tendrán que superar un simple test de razonabilidad, sin

${ }^{23}$ Como ya señalara el Tribunal en: Hague v. Committee for Industrial Organization:

"Wherever the title of streets and parks may rest, they have immemorially been held in trust for the use of the public and, time out of mind, have been used for purposes of assembly, communicating thoughts between citizens, and discussing public questions». 
que el Estado tenga que demostrar, en este caso, la existencia de un interés apremiante que legitime su política.

En definitiva, en derecho norteamericano cualquier restricción que imponga el Estado sobre la libertad de expresión, ya sea en ámbitos que puedan considerarse como foros públicos naturales, o en aquellos otros artificiales, en tanto habilitados por los poderes públicos, será contraria a la Primera Enmienda, salvo que se pueda demostrar que existía un interés verdaderamente apremiante que justifique esa prohibición.

Como es obvio y de cara al análisis de la cuestión, para valorar si el bloqueo de determinados usuarios en Twitter desde el perfil del presidente Trump ha vulnerado la Primera Enmienda, lo que nos tendremos que preguntar es si, al utilizar dicho perfil como una plataforma a través de la cual dar a la opinión pública cierta información institucional, el Presidente Trump ha creado un foro público, es decir, si estamos ante un foro designado o putativo. A este respecto, es relevante tener en cuenta que la Corte Suprema ha señalado expresamente que los foros públicos no tienen que ser espacios físicos, sino que el concepto de foro público hay que entenderlo también en un sentido metafísico, de tal forma que el mismo englobaría espacios no tangibles pero gestionados por el Estado ${ }^{24}$.

\section{2. ¿De qué hablamos cuando hablamos de Goverment Speech?}

Si nos encontramos en un foro público, el gobierno no puede discriminar por motivos ideológicos, pero si es el propio gobierno el que habla, entonces no pesa sobre él ninguna exigencia de neutralidad política y la única responsabilidad que tendrá por su discurso será de carácter político, a través de los distintos procedimientos formales e informales de rendición de cuentas, en último caso, ante el electorado. El principio que se acaba de avanzar es aquel que subyace tras la idea de government speech ${ }^{25}$, un concepto que construye la Corte Suprema en la década de los cuarenta y que ha hecho fortuna en diversos ámbitos del derecho norteamericano. Por ejemplo, en el ámbito del derecho de subvenciones, que es por otro lado donde se origina esta doctrina judicial, la Corte Suprema ha entendido que no es contrario a la Primera Enmienda que los poderes públicos discriminen a través de sus políticas

${ }^{24}$ Por ejemplo, partidas presupuestarias destinadas a financiar debates públicos a través de subvenciones editoriales Rosenberger v. Rector and Visitors of the University of Virginia, 515 U.S. 819 (1995).

${ }_{25}$ Sobre este concepto me he ocupado en extenso, en Vázquez Alonso 2017. De la bibliografía que cito en el trabajo, son especialmente relevantes los primeros trabajos de (Yudof 1979 y 1983). Para una panorámica general de la evolución del concepto en la doctrina norteamericana, véase (Bezanson 2010). 
públicas, promocionando económicamente unas opciones morales presentes en la sociedad frente a otras ${ }^{26}$. A través del concepto de Government Speech, la Corte ha entendido también que es constitucionalmente legítimo que el Gobierno facilite plataformas de su dominio a ciertos discursos vedando el acceso a otros ${ }^{27}$. Para la Corte, lo fundamental en estos casos, donde realmente nos encontramos ante un discurso híbrido, ya que son tanto el Estado como los ciudadanos los que hablan a través de una determinada plataforma, es tomar en consideración si, en último término, el Estado lleva a cabo un control sobre le mensaje, ya que si es así, hay que concluir que no se trata de un foro público (por definición ilimitado y abierto) sino de un caso de Government Speech, no sometido, por lo tanto, a ningún requisito de neutralidad derivado de la Primera Enmienda. Como puede deducirse, la cuestión que en el caso concreto se plantea es la de si puede considerarse o no que el perfil de Twitter del Presidente Trump es un ámbito propio de expresión del Government Speech, y donde, por lo tanto, no cabría ningún tipo de reproche judicial sobre la base de la Primera Enmienda. La juez de Manhattan ha entendido que no. Ahora veremos por qué.

\section{3. ¿Por qué@realDonaldTrump es un foro público?}

El ciudadano Donald Trump se dio de alta como usuario en Twitter allá por marzo de 2009 con la cuenta @realDonaldTrump, una cuenta que hoy en día es una de las dos que usa bajo el sobrenombre de 45th President of the United States of America. La segunda, creada en enero de 2017 es @Potus, si bien en esta, generada ya como presidente los USA, su carisma resulta mucho menos irresistible y ello si se comparan los 25 millones de seguidores

${ }^{26}$ Rust vs. Sullivan, 500 U.S. 173 (1991). Del mismo modo, ha considerado que no es contrario a la Primera Enmienda el compeler a los ciudadanos a financiar determinadas campañas de publicidad institucional, aun cuando éstos manifiesten su oposición de principio al contenido de dicha campaña Johanns v. Livestock Marketing Association, 544 U.S. 550 (2005).

${ }^{27}$ Pleasant Grove City v. Summum, 555 U.S. 460 (2009). El caso más emblemático y también el más reciente es Walker v. Texas Division, Sons of Confederate Veterans, en el cual, la mayoría del Tribunal sostuvo que no era contrario a la Primera Enmienda el hecho de que el Estado de Texas impidiera a una asociación de descendientes de soldados confederados el integrar la bandera de la confederación en las matrículas de sus coches, aun cuando eran muchos los diseños permitidos por el Estado, y otras asociaciones de similares características sí habían obtenido el placet para ello. Obviamente, la pregunta que aquí se hace, es la de por qué en este caso la Corte consideró que las matrículas de los coches, que son propiedad del Estado pero que se han abierto al discurso privado que los ciudadanos quieran transmitir a través de ellas, no constituyen un foro público artificial o designado. 
de los que disfruta en ella frente a los más de 57 que siguen la primera. De hecho, en el perfil de@Potus se refiere la cuenta@realDonaldTrump y son continuas además las referencias y re-tuits que desde @Potus se hacen a las entradas de@realDonaldTrump. Tampoco el propio perfil@WhiteHouse se le acerca en popularidad, con sólo 18 millones de seguidores. En este también se invita también a seguir al Presidente Trump, pero no a través de @ Potus sino de la celebérrima@realDonaldTrump.

A este respecto, puede afirmarse que el Twitter de Trump por antonomasia, aquel que ha sido fundamental tanto en su estrategia para acceder a la presidencia de los USA, como posteriormente en el ejercicio del cargo, no es otro que@realDonaldTrump, es decir, aquel perfil desde el que se produjeron los bloqueos judicializados. La primera cuestión que se plantea con respecto a la libertad de expresión de los recurrentes, es si este perfil puede considerarse un perfil institucional o si, por el contrario, hay que asumir que es un perfil privado, ya que, en este último caso, como es obvio, el ciudadano Trump sería tan libre como cualquier otro para bloquear o no el acceso de determinados usuarios a su perfil. Como se señala, Donald Trump abrió este perfil en Twitter antes de ser elegido Presidente de los Estados Unidos en 2009 , sin embargo, este dato no obsta para que la juez neoyorkino decida que dicho perfil tiene que ser considerado un perfil institucional.

Lo verdaderamente importante para el Tribunal, más allá de que la cuenta se anuncia como la del 45th President of the United States of America y que es gestionada por un empleado de la Casa Blanca, el encargado del área de social media, Daniel Scavino, es la propia relevancia institucional que el presidente Trump da a su perfil de Twitter. Como por todos es conocido, es a través de esta red social cómo Donald Trump ha informado a la ciudadanía de algunas de sus principales líneas de acción, tanto en política interior como exterior, anunciando incluso algunos de los nombramientos de funcionarios bajo su competencia, como fue el caso, tal y como recuerda la propia sentencia, del director del FBI. Es bastante significativo, por otro lado, que todas las entradas que el presidente Trump hace desde esta cuenta son subsumibles dentro del mandato de preservación de los documentos presidenciales que impone desde 1978 The Presidential Records Act $^{28}$.

En cualquier caso, por resumir, lo cierto es que si se realiza un análisis contextual de cuál ha sido el uso de este perfil por parte del presidente, no parece descabellada la conclusión a la que llega el Tribunal cuando afirma que la dimensión institucional es aquello que ha prevalecido en el uso que ha hecho Trump del perfil@ @realDonaldTrump como plataforma de

${ }^{28}$ De hecho, como insiste Siddique, ese mandato de preservación plantea con respecto a esta red social otro problema jurídico que es el de que, hasta qué punto, podrían ser eliminadas del perfil algunas de las entradas realizadas (Siddique, 2018). 
comunicación. De hecho, ésta ha sido la principal vía de publicidad de su acción de gobierno, con un éxito más que evidente si tomamos en consideración algo que permite las características de Twitter como red social, que es computar los comentarios, retuiteos, o «me gusta», que recibe cualquier tuit. Desde luego, Donald Trump ha entendido mejor que nadie las posibilidades del beatifull costraint que impone el límite de caracteres en Twitter, de cara a elaborar una continua narrativa de su acción política, con un impacto directo en la opinión pública y de proyección viral, en un ámbito donde millones de usuarios, a través del retweet y de la indexación de sus comentarios, cooperan en la difusión de su retórica ${ }^{29}$.

Pero la dimensión institucional del perfil del presidente Trump no resultaría suficiente para afirmar que el mismo pueda considerarse un public forum, ya que la característica definitoria de estos foros es que, a través de los mismos, no sólo se accede a determinada información de una forma pasiva, sino que se puede participar en ellos con las propias ideas. La propia anatomía de Twitter como red social, su diseño interactivo y su naturaleza abierta, certifican para este Tribunal que un perfil como el del Presidente, usado con una finalidad institucional, debe ser considerado como un foro público. En este sentido, si hay algo que resulta relevante de esta sentencia es observar cómo el Tribunal atiende tanto a las características tecnológicas de la red social como a la propia sociología de su uso ${ }^{30}$ para situar jurídicamente la cuestión planteada.

Una de las características de Twitter es que el denominado timeline de un determinado perfil es accesible para cualquiera, si bien, únicamente quienes son usuarios de la red social tienen la posibilidad de poder interactuar respondiendo, citando, o retuiteando los mensajes de una determinada cuenta. En este sentido, si el bloqueo a un usuario por parte del titular de una cuenta no impide que el usuario bloqueado pueda seguir conociendo de las entradas que el primero hace, incluso comentar los comentarios que otros usuarios hagan a las entradas realizadas desde dicha cuenta; lo cierto es que, al usuario bloqueado le será ya imposible interactuar directamente desde su propio perfil comentando, retuiteando, indexando, o simplemente señalando su opinión favorable con un «me gusta» a cualquier entrada realizada por el titular de la cuenta que le ha bloqueado.

Ciertamente, el bloqueo en Twitter por parte de un perfil institucional no afecta, dado el carácter abierto de esta red, al derecho a recibir información, la cual estará siempre a disposición del ciudadano, aunque no pueda verla

${ }^{29}$ De entre los incontables estudios que se han llevado a cabo en USA sobre el uso que ha hecho Trump de las redes sociales y específicamente de Twitter, puede verse el muy reciente de (Stolee y Caton, 2018).

${ }^{30}$ Knight First Amendment Institute v. Trump (pp. 3-9). 
directamente a través de su perfil de usuario. El derecho que se puede ver afectado, por lo tanto, es el derecho a la libertad de expresión, entendido este de nuevo, como el derecho que ampara nuestra libertad para acceder a los foros públicos que están bajo el control del Estado y dentro de los cuales no cabe ninguna restricción al discurso privado que no apele a un interés estatal apremiante. Lo relevante aquí será si se puede considerar o no el perfil de un cargo público en una red social como un foro bajo control del Estado. El problema conceptual que se plantea es, por tanto, si cuando hablamos de «bajo el control del Estado» queremos decir que es «propiedad del Estado»; o si, por el contrario, también puede considerarse un foro público designado o putativo, aquel que, sin ser propiedad del Estado, ha sido de alguna manera creado por éste. Sobre la base de que lo determinante para considerar si un foro es público no es la propiedad del foro sino si efectivamente existe un control gubernamental sobre el mismo ${ }^{31}$, la juez de Manhattan consideró que el perfil del presidente Trump, pese a proyectarse a través de una plataforma privada como es Twitter, sí es un foro público en tanto es una autoridad pública quien en último término lo ha creado.

En definitiva, cuando una autoridad pública decide que su canal de comunicación institucional va a ser el que ofrece una red social privada de naturaleza interactiva, estaría creando un foro público putativo o designado.

\section{4. ¿Por qué no es government speech?}

La argumentación que asume el tribunal neoyorkino en Knight First Amendment Institute vs. Trump se enfrenta a un problema de coherencia con respecto a lo que estipulan los últimos precedentes ya señalados de la Corte Suprema, en relación a cuándo nos encontramos ante un supuesto de government speech. Es decir, ante un ámbito que no puede considerarse un foro público porque quien habla en último término a través de él es el Estado, y cuando el Estado habla, éste no está sometido a las exigencias de la Primera Enmienda. Existe, por lo menos a priori, un problema de coherencia porque precisamente la Corte Suprema insistió en que en los supuestos de discurso híbrido (Corbin 2008), es decir, cuando el discurso de los ciudadanos y el del

${ }^{31}$ Cornelius vs. Naapc Leg. Def. Fund., 473 U.S. 788 (1985). Lo cierto es que la jurisprudencia de la Corte Suprema sobre el public forum no ofrece una respuesta concluyente a esta cuestión, más allá de un precedente ya lejano, Cornelius vs. Naapc Leg. Def. Fund, en el cual el Tribunal contempla la posibilidad de que incluso en ámbitos que no sean propiedad del Estado, pero donde el Estado opere en una posición dominante, nos encontremos ante un foro público. En concreto, la mayoría del Tribunal coincide en que: «Although, as an initial matter, a speaker must seek access to public property or to private property devoted to public use to evoke First Amendment». 
Estado convergen en un determinado canal de comunicación, se debe asumir que es efectivamente el Estado el que habla y, por lo tanto, que no tiene la obligación de ser neutral a la hora de dar acceso a los ciudadanos ${ }^{32}$. Trasladada esa lógica al caso que concierne, se podría pensar que, al existir un control por parte del presidente Trump sobre su perfil, la discriminación ideológica de ciertos seguidores, a través del uso de la opción de bloqueo, es un exponente del discurso gubernamental, únicamente fiscalizable a través del proceso político.

Si nos paramos a pensar, los argumentos de la defensa de Donald Trump tenían algo de contradictorios. Por un lado, se apelaba al hecho de que el perfil @ realDonaldTrump ha de considerarse un perfil privado donde el ciudadano Trump ha de disfrutar de la misma discrecionalidad para bloquear que cualquier otro usuario de Twitter. Pero, al mismo tiempo, se traía a colación la doctrina del Government Speech, llamando la atención sobre el hecho de que es el Gobierno quien habla sin que, por lo tanto, pueda exigírsele ninguna neutralidad con respecto al discurso de terceros.

En cualquier caso, la juez neoyorquina va a dar argumentos de réplica a ambas estrategias de defensa. Para ello, va a diferenciar dos momentos en relación con la actividad del presidente Trump en Twitter. Por un lado, es obvio que es suya la decisión de crear un perfil en esta red social, con lo que se puede decir que, en el origen, dicho perfil está bajo su control. Ahora bien, una vez que ha creado dicho perfil, el uso institucional que ha hecho del mismo como Presidente, unido a las propias características interactivas del medio tecnológico, que no son determinadas por él pero sí asumidas, transforma dicho espacio, en origen privado, en un foro público. La razón principal de ello es que cada entrada realizada desde el perfil @realDonaldTrump permite a un ilimitado número de usuarios participar con su discurso, no sólo en relación con el propio mensaje que el Presidente Trump ha querido compartir, sino respecto a cualquiera de los mensajes que a raíz del mismo se publican en su timeline. Sobre este foro público sobrevenido Donald Trump ya no puede ejercer ningún control que signifique desviarse de la estricta obligación de neutralidad con respecto a los distintos puntos de vista ideológicos que impone la Primera Enmienda en estos ámbitos ${ }^{33}$.

En definitiva, cuando una institución o autoridad usa una red social para hacer pública su acción de gobierno y esta red, además de convocar a un

${ }^{32}$ Por ejemplo, la Corte Suprema ha entendido recientemente que si existe un control estatal acerca de qué diseños pueden o no exhibirse en las matrículas de los coches, estas matrículas serían una manifestación del Goverment Speech, sin que pueda, por lo tanto, considerarse discriminatoria la opción de no autorizar determinados mensajes a los ciudadanos, tomando en consideración su contenido simbólico. Walker v. Texas Division, Sons of Confederate Veterans, 576 US _ (2015).

33 Knight First Amendment Institute v. Trump: (pp. 49-50). 
número abierto e indeterminado de internautas, tiene unas características interactivas, nos encontraríamos ante un foro público. Se trata, por lo tanto, de un ámbito digital donde la institución o autoridad pública que ha creado el perfil ya no puede discrecionalmente censurar determinados mensajes, haciendo uso de una herramienta, como el bloqueo que sí podrá usar cualquier usuario privado, por muchos seguidores que tenga y por muy relevante que sea el debate que genere su timeline $^{34}$.

\section{Silenciar vs. Bloquear: entre la legítima ignorancia al ciudadano y su inconstitucional exclusión del foro}

En un viejo precedente, Smith v. Arkansas State Highway Employees ${ }^{35}$, la Corte Suprema rechazó la demanda que, sobre la base de la Primera Enmienda, habían planteado unos trabajadores cuyas quejas no fueron atendidas por la empresa donde trabajaban, al ser mediadas por su sindicato, mientras que aquellos otros compañeros que directamente habían planteado al empresario sus quejas, sí obtuvieron audiencia. Para el Tribunal, «el derecho de cualquier persona a expresarse libremente no se ve vulnerado cuando el gobierno simplemente ignora a esa persona escuchando a otras». La línea que separa la diferenciación que está permitida por la Primera Enmienda de la que no, es por lo tanto aquella a partir de la cual se puede entender que los poderes públicos están, no ya ignorando sino directamente prohibiendo el ejercicio de la libertad de expresión de los ciudadanos ${ }^{36}$.

En Knight First Amendment Institute v. Trump, la juez de New York va a trasladar este precedente al contexto tecnológico del litigio, que es el de la red social Twitter, y al uso que se hace por parte de una autoridad pública de uno de los instrumentos que ésta ofrece, el del bloqueo de usuarios. En su opinión, la diferencia entre la ignorancia del ciudadano, permitida por la Primera Enmienda, y la censura de determinados discursos que ésta prohíbe, es la que existe entre el uso de la opción de silenciar que ofrece Twitter y el de la opción de bloquear. Para entender la razón de ello debemos situarnos de nuevo dentro de la lógica jurídica de los public forum. Una de las

\footnotetext{
${ }^{34}$ Knight First Amendment Institute v. Trump, (p. 43)

35 Smith v. Arkansas State Highway Employees, 441 U.S. 463 (1979).

${ }^{36}$ La lógica que subyace tras este razonamiento la vamos a encontrar años más tarde en la que puede considerarse, de hecho, la decisión fundacional de la doctrina del government speech en la Corte Suprema norteamericana: Rust vs. Sullivan. En ella, la mayoría del Tribunal entiende que el gobierno federal no ha vulnerado la Primera Enmienda al condicionar una ayuda fiscal a clínicas de planificación familiar a que éstas en ningún caso planteen el aborto como terapia. Para la Corte, el Estado debe permitir cualquier discurso, pero no tiene que subvencionarlo todo, por lo que es legítimo que privilegie determinadas posturas morales frente a otras en sus políticas públicas.
} 
características de estos espacios es que, en el seno de los mismos, se produce un proceso de comunicación que no tiene un carácter lineal, sino que son muchos los actores que participan en él a través de un diálogo no predefinido y multilateral.

Cuando se silencia a un usuario de Twitter, el titular de la cuenta ya no va a recibir la notificación de cualquier interacción que a través de su timeline haga el usuario silenciado; sin embargo, sus posibilidades de interactuar con otros usuarios a través de estos comentarios van a verse inalteradas. Es decir, que otros usuarios podrán ver los comentarios que éste haga a determinadas entradas y tendrán oportunidad de darles réplica, todo ello dentro de ese foro principal o matriz. Por el contrario, si somos bloqueados, además de perder la posibilidad de interactuar directamente con la cuenta que nos bloquea, tampoco podremos acceder a ese foro que constituyen los usuarios que siguen y comentan el timeline del perfil en cuestión. Desde luego, como se reconoce en la propia sentencia, se podría pensar que, aunque haya matices entre bloquear y silenciar, la diferencia real entre una y otra acción tampoco debería se exagerada. La realidad es que, si se toma en cuenta el propio diseño de la red social en cuestión, nada impide realmente a los usuarios bloqueados acceder a las entradas del perfil que ha ejecutado el bloqueo, e incluso comentarlas, ya sea a través de capturas de pantalla obtenidas al margen de su perfil o llevando a cabo comentarios a aquellos comentarios que a su vez otro usuario haya hecho de las entradas del perfil principal. Sin embargo, la cuestión aquí radica en que nos encontramos dentro de un foro público, y en que esa pequeña merma en las posibilidades de interacción que se derivan del bloqueo es, en último término, consecuencia de una reacción frente a la manifestación dentro de este foro de opiniones que están protegidas por la Primera Enmienda. Así, por nimias que puedan considerarse, estas trabas al ejercicio de la libertad de expresión son también contrarias a la Constitución, al producirse en un foro público, es decir, en un ámbito designado por el Estado para el intercambio de opiniones ${ }^{37}$.

\section{IV.LAS REDES SOCIALES NO SON FOROS PÚBLICOS}

Entre los diversos comentarios que se hicieron públicos inmediatamente después de conocerse la sentencia Knight First Amendment Institute v. Trump, destacan varios publicados en prensa por el profesor Noah Feld$\operatorname{man}^{38}$, una referencia en el estudio de la Primera Enmienda. Muy crítico con

${ }^{37}$ Knight First Amendment Institute v. Trump, (pp. 65-66).

38 Are You Sure You Want a Right to Trump's Twitter Account?, June 5 2018. Disponible https://www.nytimes.com/2018/06/05/opinion/first-amendment-trump-twitter. html. Igualmente, y anterior a la sentencia, puede verse Feldman, Noah (2017): «Consti- 
la decisión tomada por la juez de Manhattan, Feldman alertaba de que, de asumirse sin matices que las redes sociales son foros públicos, no sólo se estaría desdibujando hasta hacerse difícilmente reconocible la libertad de empresa, sino que toda política de autorregulación que éstas corporaciones llevaran a cabo podría considerarse contraria a las exigencias de la Primera Enmienda, ya que, como es sabido, en el ordenamiento norteamericano rige una comprensión muy generosa del contenido protegido por la libertad de expresión que alcanza a los discursos más extremos.

El comentario de Feldman, desde luego, ponía el dedo en la llaga. Si asumimos que existe una suerte de derecho de acceso al foro virtual frente a las limitaciones que quiera imponer el Estado, y si comprendemos igualmente que los perfiles que las autoridades o instituciones abran en determinadas plataformas privadas son foros públicos: ¿por qué motivo vamos a excluir de esta naturaleza a la plataforma en sí? Es decir, ¿por qué estas empresas tecnológicas sí van a poder legítimamente censurar ciertas opiniones o suprimir las cuentas de determinados usuarios, sin estar sometidas a las exigencias que se derivan de la Primera Enmienda? En definitiva, aceptando que las redes sociales son el equivalente digital, dentro del sistema de libertad de expresión, a las plazas, las calles o los parques, ¿por qué el derecho a expresarse dentro de ellas puede ser regulado al margen de las exigencias constitucionales?

La crítica de Feldman se sitúa dentro de una interpretación ortodoxa del derecho constitucional norteamericano, que pivotaría sobre dos ideas básicas. Una que, tal y como prescribe la doctrina del State Action, las exigencias derivadas de la Primera Enmienda rigen las relaciones entre los particulares y los poderes públicos pero no comprometen a las corporaciones privadas. En segundo lugar, que en ningún caso la trascendencia social de una red como Twitter puede modificar la comprensión jurídica que tenemos de este tipo de empresas. Twitter no es otra cosa que una corporación de comunicación privada y los litigios que en el seno de la misma se susciten han de ser considerados litigios entre particulares.

Desde luego, leídas aisladamente decisiones como Knight First Amendment Institute v. Trump, o la propia Packingham v. Carolina del Norte, se prestan a ser interpretadas como el primer paso en la desamortización de estos presupuestos que acabamos de enunciar. Sin embargo, al contrario de lo que sostenía Feldman, la práctica judicial posterior ha confirmado que estos presagios son bastante exagerados. Veamos.

En primer lugar, es importante acotar bien aquello que se decide en Knight First Amendment Institute vs. Trump. Una sentencia que, en un

tution can't stop Trump from blocking tweets», en Bloomberg, June 7 2018. Disponible en: https://www.bloomberg.com/opinion/articles/2017-06-07/constitution-can-t-stoptrump-from-blocking-tweets 
ejercicio loable de realismo jurídico, lo que viene a confirmar es que cuando un cargo público o una institución usan Twitter o cualquiera otra red social con similares características interactivas, además de participar de alguna forma en el libre mercado de las ideas, también lo están regulando. Desde luego, esta regulación no es proyección directa de ninguno de los poderes o competencias que la Constitución o las leyes confieren en este caso al Presidente, sino simplemente del uso que éste hace de una opción tecnológica que le ofrece la red social, como es la de bloquear ${ }^{39}$. La actividad de una institución pública desde su perfil de Twitter tendría, en este sentido, un potencial transformador de ese canal ${ }^{40}$.

Por lo tanto, aunque la importancia de Twitter como foro sea capital, en ningún momento se pone en cuestión que el mismo deje de ser un foro privado. En realidad, lo novedoso y lo audaz de esta jurisprudencia que acabamos de ver es que la misma reconoce que esta plataforma puede albergar en su seno subforos que sí pueden considerarse públicos, ya que, pese a no ser propiedad del Estados, están bajo su dominio y control.

A este respecto, la doctrina establecida en Knight First Amendment Institute vs. Trump no toma postura en el debate sobre la dimensión privada o pública de foros como los que son gestionados por Facebook, YouTube o Twitter. Un debate que, en el derecho norteamericano, gira principalmente sobre una pregunta elemental: $¡$ tienen que estar las redes sociales sometidas a las exigencias de la Primera Enmienda? Como es sabido el legislador federal dio hace tiempo una respuesta concluyente a esta pregunta a través de la celebérrima Sección 230 de la Communications Decency Act (CDA), y lo hizo, ya no sólo a través de esas veintiséis palabras que han pasado a la historia como aquellas que «crearon internet»:

No provider or user of an interactive computer service shall be treated as the publisher or speaker of any information provided by another information content provider

sino específicamente mediante la letra b) de ese mismo número, donde se establece:

${ }^{39}$ Como cierta doctrina ha señalado, si se permitiese a las instituciones o autoridades públicas el bloqueo selectivo de disidentes en este ámbito, esos espacios virtuales podrían convertirse en lugares públicos destinados al culto de la personalidad de los dirigentes (Geltzer y Marshak 2017), algo que en último término repugnaría los valores que se encuentran tras la doctrina norteamericana de la libertad de expresión.

${ }^{40}$ No hay que olvidar, en este sentido, que la doctrina de los public forum y, en concreto, la de los foros públicos artificiales o designados, presupone que sea el poder público quien habilite esos foros para el ejercicio de la libertad de expresión. Es decir, que no sólo es necesario que ese foro de opinión exista y sea concurrido, sino también que el mismo esté bajo el dominio del Estado. 
No provider or user of an interactive computer service shall be held liable on account of any action voluntarily taken in good faith to restrict access to or availability of material that the provider or user considers to be obscene, lewd, lascivious, filthy, excessively violent, harassing, or otherwise objectionable, whether or not such material is constitutionally protected. (Las cursivas son mías).

Por lo que a nosotros nos interesa, lo relevante aquí, como podemos leer, es que las redes sociales, en tanto proveedores de servicios, no sólo no son responsables por aquellos contenidos publicados por terceros ${ }^{41}$, sino que tampoco lo son por aquel contenido que, aun estando protegido por la Primera Enmienda, ellas deciden excluir. Dicho de otra forma, la Sección 230 nos dice inequívocamente que la censura privada que las redes sociales lleven a cabo en el marco de sus propias políticas de gestión de contenidos, no podrá asimilarse en su tratamiento jurídico a una censura pública, y tendrá como único límite, no la neutralidad exigible por la Primera Enmienda, sino el mucho más laxo límite de la buena fe. Pero no es sólo lo que dice la Sección 230 sino que de la propia jurisprudencia sobre la Primera Enmienda en materia de libertad de expresión podríamos deducir que, en derecho norteamericano, empresas como Facebook o Twitter están constitucionalmente amparadas para censurar aquellos contenidos que consideren no deben tener visibilidad en sus plataformas (Heins, 2014: 326, 327). A este respecto, como fácilmente puede intuirse, extender la interpretación judicial del foro público a las redes sociales implicaría tácitamente derogar uno de los dos pilares sobre los que se ha erigido en los Estados Unidos el sistema de la comunicación en red, y que es el de la indemnidad jurídica de las empresas de comunicación por aquellas políticas y acciones que tomen de cara a excluir de sus plataformas discursos que, de otro lado, no dejan de estar protegidos por la Primera Enmienda. En definitiva, para hacer que sus espacios sean como ellos quieran que sean

Las metáforas en el mundo del derecho son didácticas e ilustrativas pero normalmente tienen limitaciones y pueden generar confusión o falsas expectativas. Es cierto, en este sentido, que Twitter o Facebook hoy cumplen una función similar a la que antes cumplían los foros públicos tradicionales como las calles, los parques y las plazas, pero también lo es que Twitter o Facebook son espacios virtuales gestionados por empresas privadas. En este sentido, pese a que entiendo que es muy probable de que la doctrina esbozada en

${ }^{41}$ Son significativas, a este respecto, las diferencias en relación al régimen establecido por la Directiva 2000/31/CE de comercio electrónico, donde se establecen, como es sabido, una serie de exclusiones de responsabilidad a favor de los prestadores e intermediarios, siempre que no haya conocimiento efectivo de la ilicitud de los contenidos (artículos 12 a 15). 
Knight First Amendment Institute vs. Trump sea finalmente asumida como propia por la Corte Suprema, esto no tiene por qué significar que el debate sobre la naturaleza jurídica de las redes sociales se cierre en los USA a favor de una comprensión de estas redes como foros públicos, asumiéndose así que estas empresas ya no tienen más margen que el que tiene el propio Estado en sus calles y plazas para limitar ciertas expresiones.

Igualmente, tampoco cabe exagerar las implicaciones de la doctrina establecida por la Corte Suprema en Packingham v. Carolina del Norte. Como recordamos, a pesar de que el Tribunal insiste unánimemente en la retórica del «vasto foro democrático», en ningún caso trae a colación la doctrina de los foros públicos, y se limita a juzgar si la Primera Enmienda prohíbe al Estado - no a las propias empresas- vetar a los ciudadanos el acceso a ciertos servicios digitales de comunicación.

Para dar fundamento a estos presagios es importante destacar que la Corte Suprema norteamericana ha tenido recientemente una gran oportunidad de matizar su teoría sobre el foro público, y extender la misma a espacios abiertos a la ciudadanía en general, pero gestionados por empresas privadas. Estoy haciendo referencia al litigio Manhattan Community Access Corp. v. Halleck $^{42}$, del que muchos esperaban que pudiera dar lugar a un precedente que en el futuro sirviera para debilitar la eficacia del manto protector que la doctrina de la State Action brinda a las grandes corporaciones de la comunicación, de tal forma que pudieran enjuiciarse sobre la base de la Primera Enmienda sus políticas de control de contenidos. Dicha expectativa no se ha cumplido. En este caso, lo que se juzgaba era la conformidad con la Primera Enmienda del veto que una empresa sin ánimo de lucro, concesionaria de un canal público de televisión por cable en Manhattan, había impuesto a un par de ciudadanos que anteriormente habían emitido un reportaje muy crítico con la compañía en cuestión. En último término, estos ciudadanos entendían que la empresa que gestionaba el canal debía de ser considerada un actor estatal, y dicho canal un foro público donde cualquier decisión editorial, por lo tanto, estaría sometida a las exigencias de la Primera Enmienda. Sin embargo, para la mayoría del Tribunal, el hecho de que esta empresa privada gestionara un canal de acceso público y permitiese que diversas voces se expresen a través del mismo, no convierte a la misma en un actor estatal que haya de ser escrupulosamente neutral con todas las opiniones ${ }^{43}$. Para la Corte «una entidad pri-

${ }^{42}$ Manhattan Community Access Corp . v . Halleck, 587 US (2019).

${ }^{43}$ La Corte Suprema sí ha admitido excepcionalmente que una entidad privada pueda ser considerada como un «actor estatal» en aquellos supuestos en los que ésta ejerce «poderes tradicionalmente reservados al Estado». Ahora bien, como se subraya en la sentencia, lo cierto es que ha sido muy estricta a la hora de aplicar dicha excepción, exigiendo, además de que se trata de poderes tradicionalmente reservados al Estado, que éste los 
vada que proporciona un foro para el discurso no se transforma solo por ese hecho en un actor estatal $»^{44}$, y por lo tanto, las restricciones que ésta imponga en el acceso a dicho foro caen bajo el manto protector de la State Action.

Las consecuencias de este precedente, en el debate acerca de la naturaleza jurídica de las redes sociales y de las restricciones al discurso que en ellas puede llevarse a cabo, no se han hecho esperar. Sobre la base de Manhattan Community Access Corp. v. Halleck, la juez Margaret McKeown, del Noveno Circuito, ha negado que YouTube pueda ser considerado un foro público, y ha reafirmado así la discrecionalidad de esta plataforma para excluir determinados contenidos. Estamos hablando de la muy reciente sentencia Prager University, Plaintiff-Appellant, V. Google Llc, Fka Google, Inc.; Youtube, $L l c^{45}$, en la que se rechaza expresamente el argumento de que dada la posición hegemónica de YouTube en el mercado de las comunicaciones haya de considerarse que esta plataforma tenga que estar sometida a las exigencias de la Primera Enmienda. Todo apunta a que los términos en los que la Corte Suprema pueda juzgar una demanda similar no van a variar mucho de estos con los que el Tribunal de apelaciones sintetiza la razón de su fallo y que aquí extractamos:

«A pesar de la ubicuidad de YouTube y su papel como plataforma en el proceso de formación de la opinión pública, este sigue siendo un foro privado, no un foro público sujeto a control judicial bajo las exigencias de la Primer Enmienda» ${ }^{46}$

\section{EPÍLOGO DE URGENCIA: TRUMP V. TWITTER Y LA TENTACIÓN DEL CONTRAPODER}

No tardará en darse la oportunidad para que la Corte Suprema se pronuncie expresamente sobre si las empresas tecnológicas de comunicación que como Twitter, Facebook o YouTube, ocupan una posición casi monopolística a la hora de prestar determinados servicios en la sociedad de la información, pueden o no considerarse foros públicos. Como se acaba de defender, todo apunta a que las opciones que en un momento pudieron barajarse de que

haya desempeñado de forma «exclusiva». Una exclusividad que no se cumpliría en este supuesto, ya las licencias para operar en estos canales han sido concedidas a diferentes corporativas privadas desde su origen. Manhattan Community Access Corp . v . Halleck, 587 US , 6, 7 (2019).

44 Manhattan Community Access Corp . v . Halleck, 587 US 10 (2019).

${ }^{45}$ Prager University, Plaintiff-Appellant, v. Google Llc, Fka Google, Inc.; Youtube, Llc, Ninth Circuit, No. 18-15712, February 26, 2020.

${ }_{46}$ Prager University, Plaintiff-Appellant, v. Google Llc, Fka Google, Inc.; Youtube, Llc, Ninth Circuit, (p. 5). 
esto sucediera han quedado en buena medida neutralizadas por los últimos pronunciamientos judiciales. Esto no quiere decir que, como hemos visto, la Corte Suprema no extienda la doctrina del public forum a los foros institucionales que se creen en ciertas plataformas privadas, o que este concepto sirva como argumento para desactivar aquella normativa estatal que imponga trabas en el acceso de los ciudadanos a ciertos servicios en red. Ahora bien, de eso a hacer claudicar la doctrina de la State Action para someter el control de contenidos de las plataformas virtuales al estricto escrutinio de la Primera Enmienda dista un trecho que es, por ahora, muy poco probable que se vaya a recorrer.

Ahora bien, en el momento en que cierro estas páginas la relación entre Trump y Twitter vuelve a ser objeto de interés jurídico, ahora por motivos diferentes, aunque en el trasfondo está de nuevo la cuestión de la naturaleza jurídica de la red social. El origen del litigio, en este caso, se encuentra en la reacción del Presidente al hecho de que la compañía de comunicación haya etiquetado una entrada desde el perfil @realDonaldTrump como información dudosa, invitando a los usuarios a verificar la misma a través de recursos digitales puestos a disposición por la propia red social ${ }^{47}$. La reacción del Presidente Trump, a este respecto, ha sido expedir una orden ejecutiva dirigida a los diferentes departamentos y agencias federales, con el fin de limitar la inmunidad de las redes sociales por los contenidos publicados por terceros ${ }^{48}$. Dicha orden expone con claridad cuáles son sus razones ${ }^{49}$. Para el Presidente, si estas plataformas no son estrictamente neutrales en su función de intermediación, sino que, como en este caso, editan sus contenidos, las mismas han de ser comprendidas desde un punto de vista jurídico del mismo modo que lo son los medios de comunicación clásicos y, por lo tanto, han de estar sometidas a un mismo régimen de responsabilidad.

Lo cierto es que resulta poco probable que la orden ejecutiva aprobada por el Presidente vaya a tener efectos significativos en el ordenamiento americano. Los principales destinatarios de esta orden, que son la Comisión Federal de Comercio y la Comisión Federal de Comunicaciones, son agencias independientes de cuyos responsables es difícil esperar que sigan unas

${ }^{47}$ Sobre los pormenores de este suceso, puede verse: «Twitter's decision to label Trump's tweets was two years in the making», The Washington Post, May 30, 2020, disponible en https:/www.washingtonpost.com/technology/2020/05/29/inside-twittertrump-label/

${ }_{48}$ Executive Order on Preventing Online Censorship, May 28, 2020, disponible en: https://www.whitehouse.gov/presidential-actions/executive-order-preventing-onlinecensorship/

${ }^{49}$ En ellas pueden apreciarse ciertos ecos de Delfi, en referencia a la conocida jurisprudencia de la Gran Sala del Tribunal Europeo de Derechos Humanos: Delfi v. Estonia, TEDH, Gran Sala, de 15 de junio de 2015. 
instrucciones presidenciales que se apartan de forma explícita de lo prescrito por una ley federal que lleva más de veinte años en vigor ${ }^{50}$. Para que el régimen de responsabilidad de estas compañías variase, y en concreto, para que se ponga fin el principio general de inmunidad por los contenidos publicados por terceros, sería necesaria una derogación de la propia Sección 230, algo que exige una ardua tarea parlamentaria y, desde luego, mayorías nada fáciles de conseguir, aunque nada es imposible. En cualquier caso, dicha derogación espolearía sin duda otro debate ya abierto en la doctrina norteamericana y que es el de si la inmunidad de las redes por los contenidos publicados por terceros es una opción del legislador o bien una exigencia derivada de la Primera Enmienda. No podemos extendernos aquí sobre esa discusión pero es bastante significativo, a este respecto, que en uno de sus últimos números la Harvard Law Review publicara una extensa «nota» sosteniendo precisamente esta última tesis: que la inmunidad de las redes no descansa en la ley sino en la propia Constitución (Note, 2019).

Finalmente, y aunque sea de forma superficial, creo que cabe hacer una mínima reflexión acerca de los elementos diferenciales que persisten entre la comprensión jurídica que se hace en el derecho norteamericano de plataformas digitales como Twitter, Facebook o Google, y la que se produce a partir el derecho de la Unión Europea. Desde luego, los desafíos que plantea el nuevo sistema de libertad de expresión en los USA no son nada originales ni específicos $^{51}$. Las campañas de desinformación, la difusión de discurso extremo, la utilización ilícita de datos personales, el uso de algoritmos opacos para el control de contenidos, la censura ideológica... son problemas comunes al uno y al otro lado del Atlántico ${ }^{52}$. Ahora bien, a diferencia de lo que, como hemos podido ver, ocurre en los Estados Unidos, en el derecho europeo se asume de una forma más realista lo indispensable de estas plataformas virtuales para la consecución de ciertos fines públicos. Se impone, si

${ }^{50}$ Puede leerse el comentario urgente que publica el profesor Tim $\mathrm{Wu}$, Trump's Response to Twitter Is Unconstitutional, june 2, 2020, disponible en: https://www.nytimes. com/2020/06/02/opinion/trump-twitter-executive-order.html

51 Para una síntesis comparativa, puede verse (Cotino, 2017).

${ }_{52}$ Creo que es válida la tesis de Balkin quien representa los problemas actuales de la libertad de expresión con la forma de un triángulo. La dinámica de tensión que se produciría dentro de esa geometría respondería a lo siguiente. En primer lugar, los Estados trata de conseguir que las empresas digitales incorporen a su regulación interna los principios clásicos que han regido el sistema de la libertad de expresión. Por otro lado, estas empresas ponen en práctica subsistemas tecnológicos de control muy complejos, una burocracia privada poco transparente y al margen de cualquier garantía procesal que se impone a los usuarios. Estos usuarios finales, que cerrarían el triángulo, se encontrarían así en una situación de vulnerabilidad, expuestos, en definitiva al control y la manipulación digital (Balkin, 2012: 215-217) 
se me permite, y a pesar de que son muy significativas las diferencias regulatorias entre los Estados, una progresiva comprensión vicarial de estas plataformas, empleada aquí la expresión en el sentido católico del término. Es decir, existe, a este respecto, una tendencia a delegar en éstas las veces del Estado, para que las mismas ejerzan sus facultades y jurisdicción ${ }^{53}$, allí donde las propias instituciones estatales tienen dificultades para llegar a tiempo y ser efectivas ${ }^{54}$.

A este respecto, creo que en el contexto europeo la comprensión de estas compañías ya ha trascendido ampliamente la idea de que las mismas sean meras corporaciones que prestan servicios de comunicación. El nuevo nomen iuris de estos prestadores de servicios no está acotado, pero es poco discutible el hecho de que cumplen de una forma casi monopolística funciones de interés general y de que en muchos aspectos constituyen instituciones básicas del sistema democrático ${ }^{55}$. Avanza, de alguna manera, la idea de que las normas comunitarias con las que estas empresas disciplinan el discurso público en sus foros tienen que estar reguladas con un mínimo nivel de sintonía respecto a las propias reglas y principios que comprometen al Estado, y que por ello, son trasladables a estas plataformas ciertas exigencias de transparencia en la aplicación de los criterios de control que establecen, lo que incluye, claro está, a los dispositivos algorítmicos utilizados (Boix, 2020; Teruel, 2017: 100-101).

Creo, en este sentido, que vale la pena apartarse de la rigidez conceptual con la que en el derecho norteamericano se asume que cualquier labor de censura por parte de las empresas tecnológicas de comunicación cae bajo el amparo de la Primera Enmienda, y atender al hecho incontrovertible de que éstas poseen hoy en

${ }^{53}$ Es obligada la referencia aquí a: Google Spain, S.L. y Google Inc. contra Agencia Española de Protección de Datos (AEPD) y Mario Costeja González Sentencia del Tribunal de Justicia (Gran Sala) de 13 de mayo de 2014.

${ }^{54}$ La profesora Rodríguez-Izquierdo ha calificado, en mi opinión con acierto, a estas empresas, y sobre la base de la función que les es atribuida en la protección de la privacidad de sus usuarios, como «agentes de seguridad interpuestos», llamando la atención, en este sentido, sobre el hecho de que aunque probablemente «estos perfiles comerciales no sean las más indicadas para erigirse, o ser erigidas, como garantes interpuestos de bienes constitucionales son esas, las empresas tecnológicas, y sobre todo las grandes plataformas y soportes de software, las que verdaderamente están en posición de hacerlo» (Rodríguez Izquierdo, 2019).

${ }_{55}$ A este respecto, vale la pena leer el trabajo que al hilo de la Propuesta de Reglamento del Parlamento Europeo y del Consejo para la prevención de la difusión de contenidos terroristas en línea, presentada por la Comisión Europea en septiembre de 2018, elabora Germán Teruel y el que se insiste sobre la necesidad de ser cautos y ponderar el impacto que puede tener sobre la libertades comunicativas, la delegación en las redes sociales de tareas de control del discurso extremo. (Teruel, en prensa: en especial pp. 19-23 del texto manuscrito). 
día, una capacidad para determinar qué se puede decir o qué superior a la de cualquier Tribunal, y todo ello a través de procedimientos opacos y desde luego alejados de las garantías que se aplican a cualquier restricción de las libertades de expresión e información que lleven a cabo los poderes públicos. En definitiva, la censura privada en las redes, no deja de ser al mismo tiempo una censura de trascendencia pública, sobre la que se han de proyectar, por lo tanto, los principios constitucionales que regulan el discurso público. Esto no tiene ni puede significar, desde luego, que se neutralice el ámbito de autonomía de estas corporaciones, de tal manera que las mismas no puedan dibujar ciertos contornos en cuanto a lo que no desean ver en su foro; se tata, por lo tanto, de encontrar un equilibrio que tenga en cuenta que la preservación de un debate democrático abierto y vivo es también una exigencia constitucional a considerar y no una medida de gracia de estas empresas (Teruel, 2017). Ahora bien, como recientemente hemos podido ver en Italia, a propósito de dos resoluciones judiciales contradictorias, en relación la clausura por parte de Facebook de cuentas vinculadas a organizaciones de extrema derecha ${ }^{56}$, el problema reside en que en muchas ocasiones los

${ }^{56}$ El relato de los hechos, en ambos casos, es prácticamente idéntico. La red social Facebook, sobre la base de sus normas internas y, en concreto, sobre el conocido «estándar número 13 de la Comunidad», que excluye el discurso del odio en la red, cancela dos cuentas de sendas organizaciones de extrema derecha italianas, Casa Pound y Froza Nuova. Pero si los antecedentes de hecho son prácticamente fungibles en este caso, la aproximación jurídica de los jueces italianos será radicalmente diferente en uno y otro caso. Se trata, en realidad, de decisiones que parten de ideas enfrentadas sobre el derecho a la libertad de expresión y el pluralismo, pero que, en buena medida, coinciden tácitamente en lo que se refiere a la comprensión de la naturaleza jurídica de las redes sociales como espacios hegemónicos de comunicación pública. Para el Tribunal que conoce del caso Casa Pound, la cancelación de una cuenta vinculada a una asociación de carácter político, por la orientación ideológica de sus comentarios, distorsiona el valor constitucional del pluralismo político, al impedir la que no deja de ser una opción ideológica legítima en la sociedad italiana, participar plenamente en el debate público. Facebook, al igual que otras redes sociales, «ocupa una posición particular en su relación con los usuarios», y por eso su relación con quienes utilizan sus servicios «no es exactamente asimilable a la de dos sujetos privados». Esta circunstancia tiene una consecuencia jurídica fundamental y es que Facebook, a hora de decidir negar sus servicios a un usuario, tiene que tomar en consideración el marco constitucional de la libertad de expresión y no imponer más restricciones de acceso que las que el ordenamiento italiano impone al discurso público. Por su parte, el juez que conoce del recurso de Forza Italia, toma en consideración la posición institucional de las redes sociales en el sistema de la libertad de expresión, solo que en este caso pone el acento en los riesgos que desde la perspectiva de la tutela de ciertos valores constitucionales acarrea las posibilidades tecnológicas que la red ofrece a cualquier discurso de amplificar su voz y con ello sus efectos en el ciberespacio. A partir de ahí, la sentencia hace un esfuerzo por sintetizar los principales hitos normativos tanto en el ámbito de las instituciones europeas, como en el propio derecho italiano, en lo que se refiere a la lucha contra el denominado «discurso del odio» para evidenciar que la realidad normativa en 
juristas no terminamos de ponernos de acuerdo sobre cuáles son las propias exigencias que se derivan, con respecto a la libertades de expresión e información, de un determinado marco constitucional. La discusión sobre la libertad de expresión en la red no deja de esconder en muchos casos la vieja disputa, previa sin duda a la revolución tecnológica, sobre qué grado de militancia democrática impone un modelo de sociedad pluralista y los límites que sobre el discurso público se derivan de ello ${ }^{57}$.

En cualquier caso, como hemos visto, el vigor de la doctrina de la State Action, y la propia cultura jurídica del «puerto seguro» que ha generado los años de vigencia de la Sección 230, siguen marcando con nitidez en los USA, la frontera entre lo que las grandes compañías tecnológicas de comunicación significan realmente y la comprensión jurídica que se tiene de las mismas. No obstante, nada nos dice que cosas no puedan cambiar. No ya sólo porque la propia posición monopolística de empresas como Twitter pueda ser puesta en cuestión con la irrupción de corporaciones que compitan prestando servicios similares, sino porque las propias corporaciones hoy hegemónicas incorporen prácticas más propias del clásico cuarto poder que de instituciones en principio neutrales, o caracterizadas por la mera intermediación ${ }^{58}$. Cuanto

Italia es una realidad no relativista frente a cierto tipo de discursos como aquel que esta asociación transmite a través de su perfil. A este respecto, la conclusión del Tribunal es que Facebook, no sólo no ha vulnerado el derecho a la libertad de expresión y el pluralismo político al inhabilitar el perfil de usuario de esta asociación política, sino que con dicha decisión la red social estaba cumpliendo con un deber jurídico. A este respecto, como no podía ser de otra manera, se da una especial relevancia al Código de conducta para la lucha contra la incitación al odio en Internet, suscrito en mayo de 2006, ante la Comisión Europea, por las principales empresas tecnológicas. Se trataba, por lo tanto, no ya de una legítima aplicación de las cláusulas contractuales preestablecidas, en relación a qué tipo de discursos no son tolerados por la red social, sino directamente de una decisión informada por las exigencias tanto del derecho interno italiano como del derecho internacional. Las sentencias referenciadas son Tribunale di Roma, Sezione specializzata in materia di Sezione specializzata in materia di Impresa, RG 59264/2019, disponible en:

https://globalfreedomofexpression.columbia.edu/wpcontent/uploads/2020/01/sentenzacpifb.pdf y 2019 Tribunale Ordinario di Roma Sezione Diritti Della Persona E Immigrazione Civile, N. R.G. 64894/2019, disponible en http://www.questionegiustizia.it/doc/ Ordinanza-RG-648942019-Forza-Nuova-art700.pdf

57 Véase, por ejemplo, en la doctrina italiana (Caruso, 2020) Para este autor, los presupuestos pluralistas de un ordenamiento como el italiano, se deben imponer, «no solo al poder público sino también a las tecnoestructuras privadas que poseen, en virtud de su posición fáctica, las claves para acceder al discurso público». Las redes sociales, desde esta perspectiva, serían foros públicos donde cualquier restricción que se imponga al acceso de ciertos discursos ha de ser escrutada a la luz de los límites generales que el ordenamiento impone a la libertad de expresión.

${ }_{58}$ Esta tesis la sostiene en profundidad $\mathrm{Wu}$, en un trabajo que es referencia obligada dentro del debate sobre la «censura colateral» en la red. Para este autor: «When interme- 
más se aproxime la práctica de estas corporaciones a esa tarea de contrapoder más posibilidades existen de que su régimen de responsabilidad se asimile al que rige para las empresas editoriales. A esto apunta la orden ejecutiva del Presidente Trump, y creo que vale para esta ocasión la máxima del maestro Mairena de que la verdad es la verdad, dígala Agamenón o su porquero.

\section{BIBLIOGRAFÍA}

Alcácer Guirao, Rafael, Víctimas y disidentes. El «discurso del odio» en EE.UU. y Europa, Revista española de derecho constitucional, Año ${ }^{\circ} 35, \mathrm{~N}^{\circ} 103,2015$, 45-86.

BALKIN, Jack M., Free Speech is a Triangle (May 28, 2018). Columbia Law Review, 2018, Forthcoming; Yale Law School, Public Law Research Paper No. 640. Disponible en SSRN: https://ssrn.com/abstract=3186205

BARNETT LidSKY, Lyrissa (2011): «Public Forum 2.0», en Boston University Law Review, vol. 91, núm. 155, 1975-2028.

BeZanson, Randall P. (2010): «The Manner of Government Speech», en University of Iowa, College of Law, núm 10-09, 808-817.

BoIx PALOP, Andrés, (2002), «Libertad de expresión y pluralismo en la Red», Revista Española de Derecho Constitucional, n. 65, 2002, pp. 133-180.

- (2016), La construcción de los límites a la libertad de expresión en las redes sociales, Revista de estudios políticos, (Ejemplar dedicado a: Democracia y Derecho en la era de Internet: balance y perspectivas), 55-112.

- (2020), Los algoritmos son reglamentos: la necesidad de extender las garantías propias de las normas reglamentarias a los programas empleados por la administración para la adopción de decisiones Revista de Derecho Público: Teoría y Método, Vol. 1, pp.223-270, Disponible en: https://www.uv.es/collaborativeeconomy-digital-transformation-chair/en/novedades-1286057015758/Novetat. html?id=1286117933247

Caruso, Corrado, (2020) I custodi di silicio. Protezione della democrazia e libertà di espressione nell'era dei social network, en Liber Amicorum per Paquale Costanzo, http://www.giurcost.org/LIBERAMICORUM/caruso_scrittiCostanzo.pdf

Corbin, Caroline Mala (2008): «Mixed speech: when speech is both private and Governmental», en New York University Law Review, vol. 83, 101-189.

Cotino Hueso, Lorenzo (2017): Responsabilidad de intermediarios y prestadores de servicios de internet en Europa y Estados Unidos y su importancia para la libertad de expresión. Revista de Derecho, Comunicaciones y Nuevas Tecnologías, (17). Universidad de los Andes (Colombia). http://dx.doi.org/10.15425/redecom.17.2017.0.

De Miguel BÁrCEnA, Josu (2016): «Las transformaciones del derecho de la información en el contexto del ciberperiodismo», Revista de estudios políticos, (Ejemplar

diaries are actually original speakers, and have the incentives of original speakers, immunity is no longer appropriate». (Wu, 2013: 349). 
dedicado a: Democracia y Derecho en la era de Internet: balance y perspectivas), 141-168.

FELDMAN, Noah (2018): «If Trump can't block Twitter users, Twitter can't either», en Bloomberg, 24 de mayo. Disponible en: «https://www.bloomberg.com/opinion/articles/2018-05-24/trump-twitter-blocking-ruling-is-badfor-free-speech».

(2017): «Constitution can't stop Trump from blocking tweets», en Bloomberg, 7 de junio. Disponible en: https://www.bloomberg.com/opinion/articles/2017-06-07/constitution-can-t-stop-trump-from-blocking-tweets

- (2017)Are You Sure You Want a Right to Trump's Twitter Account?, June 5 2018. https://www.nytimes.com/2018/06/05/opinion/first-amendment-trumptwitter.html

Geltzer, Joshua y MarshaK, Amy, (2017): «Why the First Amendment constrains Trump's use of Twitter», en Jut Security, 6 de noviembre. Disponible en: «https://www.justsecurity.org/46760/trump-twitter-amendment/»

GeY, Steven (1998): «Reopening the Public Forum-From Sidewalks to Cyberspace», en Ohio State Law Journal, vol. 58, núm. 5, 1535-1634.

Goldberg, David T. and R. Zhang, Emily (2017), Our Fellow American, the Registered Sex Offender, en Cato Supreme Court Review, 59-103.

HABERMAS, Jürgen (2002), Teoría de la acción comunicativa (vol. 1). Madrid: Taurus. Historia y crítica de la opinión pública. La transformación estructural de la vida pública. Barcelona.

(1992), Historia y crítica de la opinión pública, 2009, Barcelona.

HeIns, Marjorie (2014), The Brave New World Of Social Media Censorship, en Harvard Law Review Forum, $n^{\circ} 126,325-330$, disponible en http://cdn.harvardlawreview.org/wpcontent/uploads/2014/06/vol127_Heins.pdf

Note, (2018) «Section 230 as First Amendment Rule», en 131 Harvard Law Review 2027.

Ott, Brian L. (2018): «The age of Twitter: Donald J. Trump and the politics of debasement», en Critical Studies in Media Communication, vol. 34, núm. 1, 59-68.

Presno Linera, Migual y Teruel Lozano, Germán (2017), La libertad de expresión en América y Europa, Juruà, Juritiba.

RODRÍGUEZ IZQuIERDO, Miryam, (2013), Internet entre otros medios o las distinciones mediáticas del Tribunal Supremo de los EEUU, en Libertad de expresión e información en Internet: amenazas y protección de los derechos personales / Loreto Corredoira y Alfonso (dir.), Lorenzo Cotino Hueso (dir.), 99-118.

— (2019), Las empresas tecnológicas en internet como agentes de seguridad, Revista Española de Derecho Constitucional, 117, septiembre-diciembre, pp. 77100.

Siddique, Bryan Christopher (2018): «Tweets That Break the Law: How The President's@RealDonaldTrump Twitter Account Is A Public Forum And His Use of twitter Violates The First Amendment And The President Records Act», en Nova Law Review, vol. 42, núm. 2, 317-352.

Stolee, Galen y Caton, Steve (2018): «Twitter, Trump, and the Base: A Shift to a New Form of Presidential Talk?», en Sings and Society, vol. 6, núm. 1, 147-165.

Teruel Lozano, Germán (2017), «Libertades comunicativas y censura en el entorno tecnológico global», Revista de la Escuela Jacobea de Posgrado [en línea], n. 12, 
2017, pp. 75-102. Disponible en: http://revista.jacobea.edu.mx/n12/4.Censura en_Internet.German_Teruel.pdf

(2019), Una lectura garantista de las nuevas tendencias en la lucha europea contra la difusión de mensajes terroristas en Internet, (en prensa).

VÁzquez Alonso, Víctor Javier (2017): «La neutralidad del Estado y el problema del government speech», en Revista de Estudios Políticos, núm. 177, 13-55.

Tiм, Wu (2020): https://www.nytimes.com/2020/06/02/opinion/trump-twitter-executive-order.html.

Wu, Felix T., (2013), Collateral Censorship and the Limits of Intermediary Immunity, 87 Notre Dame L. Rev. 293, Available at: http://scholarship.law.nd.edu/ndlr/ vol87/iss $1 / 6$

YuDOF, Mark George (1979): When Governments Speak: Toward a Theory of Government Expression and the First Amendment, 863-918 Disponible en: «https:// scholarship.law.berkeley.edu/cgi/viewcontent.cgi? article $=3231 \&$ conte $\mathrm{xt}=$ facpubs» [Consultado el 23 de diciembre de 2019].

- (1983): «Review: Government Speech and the Falsification of Consent», en Harvard Law Review, vol. 96, núm. 7, 1745-1757. 


\title{
TWITTER NO ES UN FORO PÚBLICO PERO EL PERFIL DE TRUMP SÍ LO ES. SOBRE LA CENSURA PRIVADA $D E$ Y EN LAS PLATAFORMAS DIGITALES EN LOS EE UU
}

\author{
Twitter is not a public forum, but Trump's profile is. on \\ private censorship of and on digital platforms in the USA
}

\author{
Víctor J. Vázquez Alonso \\ Profesor de Derecho Constitucional \\ Universidad de Sevilla
}

http://dx.doi.org/10.18543/ed-68(1)-2020pp475-508

\section{Copyright}

Estudios de Deusto es una revista de acceso abierto, lo que significa que es de libre acceso en su integridad. Se permite su lectura, la búsqueda, descarga, distribución y reutilización legal en cualquier tipo de soporte sólo para fines no comerciales, sin la previa autorización del editor o el autor, siempre que la obra original sea debidamente citada y cualquier cambio en el original esté claramente indicado

Estudios de Deusto is an Open Access journal which means that it is free for full access, reading, search, download, distribution, and lawful reuse in any medium only for non-commercial purposes, without prior permission from the Publisher or the author; provided the original work is properly cited and any changes to the original are clearly indicated. 